\title{
Het syndroom van Peutz-Jeghers
}

Het syndroom van Peutz-Jeghers is een zeldzame, erfelijke aandoening die wordt gekenmerkt door mucocutane pigmentaties, gastro-intestinale polyposis en een verhoogd kankerrisico. Het wordt veroorzaakt door mutaties in het LKB1-gen waardoor op jonge leeftijd hamartomen ontstaan die leiden tot buikpijn, anemie of acute darmobstructie. Patiënten hebben een verhoogd risico op het krijgen van kanker in zowel het maag-darmkanaal als in andere organen. Vanwege het complicatierisico van de darmpoliepen en het verhoogde kankerrisico is de zorg voornamelijk gericht op regelmatige controle. Maag en colon worden regelmatig endoscopisch onderzocht, de dunne darm door radiologisch onderzoek met behulp van kernspinresonantie en regelmatige controle van de pancreas met beeldvormende technieken lijkt geïndiceerd. Vrouwen wordt geadviseerd vanaf jonge leeftijd regelmatig borsten gynaecologisch onderzoek te laten doen. De pathogenese van hamartomen en carcinomen is onduidelijk. Moleculair onderzoek kan leiden tot gerichte medicamenteuze behandeling van patiënten met het syndroom van Peutz-Jeghers.

Korsse SE, Leerdam ME van, Dekker E. Het syndroom van Peutz-Jeghers

Ned Tijdschr Tandheelkd 2013; 120: 12-16

doi: $10.5177 /$ ntvt.2013.01.12215

\section{Inleiding}

In 1921 verscheen in het Maandblad der Geneeskunde een artikel van de internist Jan Peutz, destijds werkzaam in het Westeinde Ziekenhuis in Den Haag. Hij beschreef een familie waarin "zoowel neus-en keelpolypen als tegelijkertijd ook polypen van den tractus intestinalis" voorkwamen. Bovendien vertoonden dezelfde leden uit het gezin opvallende pigmentaties in het gezicht en op de slijmvliezen van de mond. Ruim 20 jaar later, in 1944, beschreef de Amerikaanse arts Harold Jeghers 2 patiënten met dezelfde verschijnselen en in 1949 publiceerde hij met 2 collega's de definitieve beschrijving van het syndroom in het New England Journal of Medicine. Uiteindelijk werd in 1954 het eponiem het syndroom van Peutz-Jeghers geïntroduceerd. De eerste kennisgeving van de typische pigmentaties stamt echter al uit 1896, toen in Engeland een tweeling werd beschreven met zwarte pigmentvlekken op de lippen en in de mond. Een van de tweeling overleed op 20-jarige leeftijd aan een invaginatie, de ander aan borstkanker op een leeftijd van 52 jaar. Tegenwoordig wordt het syndroom van Peutz-Jeghers beschreven als een erfelijke aandoening die klinisch wordt gekenmerkt door mucocutane pigmentaties, gastro-intestinale polyposis en een verhoogd kankerrisico. De klinische diagnose wordt gesteld aan de hand van de criteria van de World Health Organization (tab. 1). Het syndroom is zeldzaam, met een geschatte incidentie tussen de 1:50.000 en 1:200.000 levend geborenen. Op

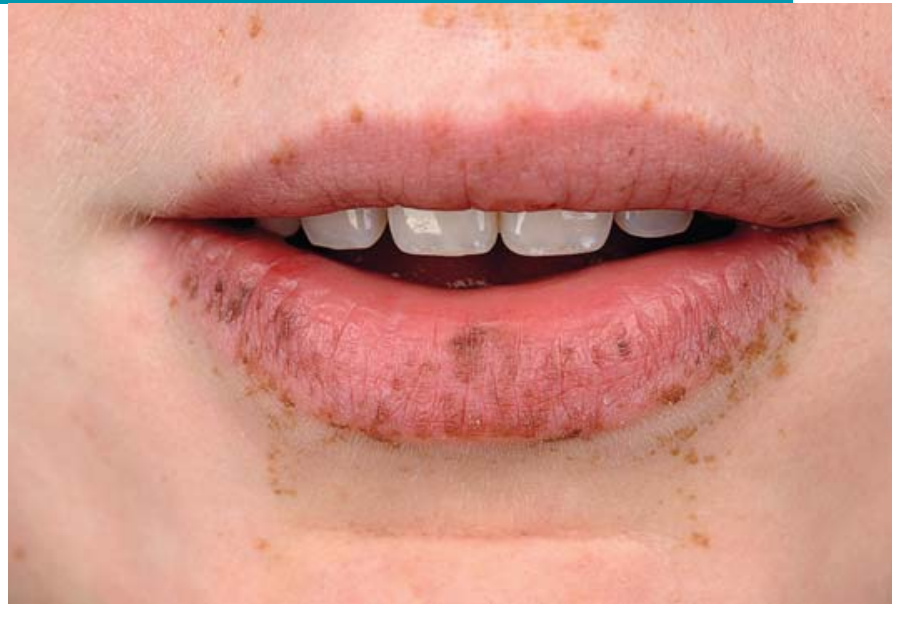

Afb.1. Typische pigmentaties op en rond de lippen van een patiënt met het syndroom van Peutz-Jeghers.

Bij een negatieve familieanamnese voor het syndroom van Peutz-Jeghers

a. 1 of meer histologisch bevestigde gastro-intestinale poliepen en karakteristieke pigmentaties van huid en slijmvliezen

b. 3 of meer histologisch bevestigde gastro-intestinale poliepen

Bij een positieve familieanamnese voor het syndroom van Peutz-Jeghers

a. 1 of meer gastro-intestinale poliepen

b. karakteristieke pigmentaties van huid en slijmvliezen

Tabel 1. De klinische diagnose van het syndroom van Peutz-Jeghers wordt gesteld aan de hand van criteria van de World Health Organization (Bosman, 2010).

dit moment zijn er circa 100 levende patiënten met het syndroom van Peutz-Jeghers in Nederland, afkomstig uit ruim 60 families, waaronder de originele 'Peutz-familie'.

\section{Genetische achtergrond}

Het syndroom van Peutz-Jeghers wordt veroorzaakt door een kiembaanmutatie in het LKB1-gen (ook bekend als STK11); een tumorsuppressorgen gelegen op chromosoom 19 van het menselijk genoom (Hemminki et al, 1998). Met de huidige technieken kan in 80-94\% van de mensen met klinische kenmerken van het syndroom van Peutz-Jeghers een mutatie in het LKB1-gen worden aangetoond. In ongeveer tweederde van de gevallen is sprake van een puntmutatie. Het syndroom erft autosomaal dominant over en bij circa $25 \%$ van de patiënten betreft het een de novo mutatie. Ondanks diverse onderzoeken is tot nu toe geen duidelijke genotype-fenotypecorrelatie aangetoond voor het syndroom van Peutz-Jeghers. Ook zijn geen verschillen in symptomen gevonden tussen patiënten met en zonder aangetoonde mutatie in het LKB1-gen. 


\section{Klinische kenmerken}

Mucocutane pigmentaties komen voor bij zo'n 95\% van de patiënten met het syndroom van Peutz-Jeghers en kunnen de eerste klinische aanwijzing zijn voor de diagnose (afb. 1). De pigmentaties ontstaan tijdens de kinderleeftijd, soms al in het eerste levensjaar, en worden voornamelijk gezien op en rond de lippen. Ze kunnen ook zichtbaar zijn op het wangslijmvlies, rond de neusvleugels, op de handen en voeten of in de perianale regio. Ze zijn vlak, blauw-grijs van kleur en variëren in grootte van 1 tot $5 \mathrm{~mm}$ en kunnen aanwezig zijn voordat de ziekte zich manifesteert in het maag-darmkanaal. De pigmentaties worden veroorzaakt door hyperpigmentatie van basaalcellen en hyperplasie van melanocyten (Lodish en Stratakis, 2011). De grootte en intensiteit van de melaninepigmentaties wordt niet beïnvloed door zonlicht, in tegenstelling tot gewone sproeten. Hoewel er geen bewijs is dat de pigmentaties bij het syndroom van Peutz-Jeghers maligne kunnen ontaarden, kan het esthetisch effect hinderlijk zijn voor de patiënt. Bij het merendeel van de patiënten vervagen de pigmentaties echter tijdens de puberteit

Patiënten met het syndroom van Peutz-Jeghers kunnen al vanaf jonge leeftijd gastro-intestinale poliepen ontwikkelen. Bij meer dan 90\% van de patiënten bevinden de

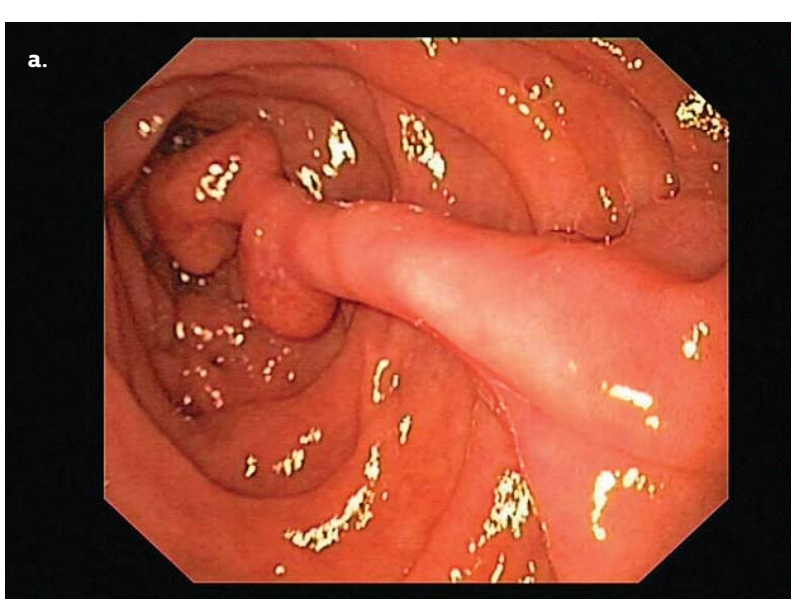

Afb. 2. a. Endoscopische afbeelding van een gesteelde poliep in de dunne darm van een patiënt met het syndroom van Peutz-Jeghers.

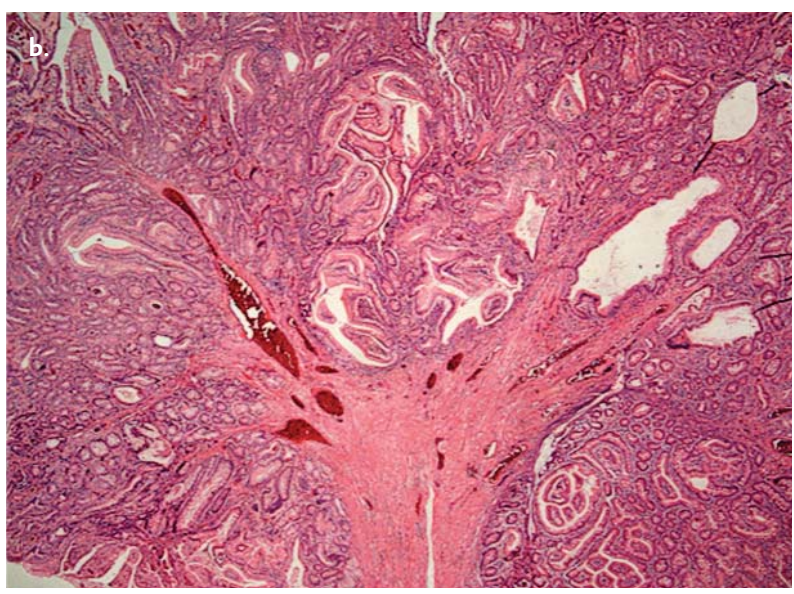

b. Weefsel van een hamartoom, met de typische kern van vertakkend glad spierweefsel.

\section{Intermezzo 1}

Een man van 22 jaar presenteerde zich op de afdeling Spoedeisende Hulp van een medisch centrum met acute hevige buikpijn en bewegingsdrang. Op verdenking van een acute darmafsluiting werd een spoedlaparotomie verricht. Er bleek sprake van een dunne darminvaginatie, veroorzaakt door een poliep van $3,5 \mathrm{~cm}$ die werd verwijderd. Histologisch onderzoek toonde de karakteristieke kenmerken van een hamartoom, passend bij het syndroom van Peutz-Jeghers. Bij navraag bleek de man als kind 'sproeten' op zijn lippen en rond zijn mond te hebben gehad. Hij werd verwezen naar een klinisch geneticus. Uit de familieanamnese bleek het voorkomen van verschillende kankers bij familieleden op betrekkelijk jonge leeftijd. Bij genetisch onderzoek werd een mutatie in het LKB1-gen gevonden. De diagnose 'syndroom van Peutz-Jeghers' werd gesteld en de man onderging vervolgens regelmatige controles van maag, dunne darm en dikke darm, waarbij steeds hamartomen werden verwijderd. De man kreeg 2 dochters en een zoon. Zijn beide dochters bleken ook drager van de mutatie in het LKB1-gen en ook zij ondergingen regelmatig controle. Op 54-jarige leeftijd presenteerde hij zich bij een maag-darm-leverarts met klachten van gewichtsverlies en icterus. Beeldvormend onderzoek liet een ruimte-innemend proces in de pancreaskop zien. Histologisch onderzoek toonde een adenocarcinoom van de pancreas met metastasen in de lever. Hij overleed een half jaar na de diagnose. poliepen zich in de dunne darm, voornamelijk in het jejunum, maar ze worden ook gevonden in de maag en de dikke darm. In zeldzame gevallen worden hamartomen gevonden in andere organen zoals de galblaas, de longen, de blaas, de ureter en de nasofarynx. Histologisch bestaan de poliepen uit een kern van vertakkend glad spierweefsel, vaak uitlopend in een lange steel (afb. 2). Aangezien de poliepen zijn omlijnd met normaal darmepitheel, worden ze hamartomen genoemd. De grootte en het aantal poliepen wisselt sterk per patiënt. Hamartomen kunnen leiden tot symptomen van buikpijn, acuut of chronisch gastro-intestinaal bloedverlies, anemie en obstructieklachten door darminvaginatie. Een derde van de patiënten met het syndroom van Peutz-Jeghers heeft symptomen voor het tiende levensjaar en op een leeftijd van 20 jaar heeft 50\% poliepgerelateerde klachten. Het cumulatieve risico voor het krijgen van een invaginatie is $50 \%$ op 20-jarige leeftijd (Van Lier et al, 2011a). Patiënten presenteren zich meestal met acute, hevige buikpijn en in de meeste gevallen is direct chirurgisch ingrijpen vereist. In het verleden waren invaginaties de belangrijkste doodsoorzaak voor patiënten met het syndroom van Peutz-Jeghers. Hoewel niet alle grote poliepen klachten veroorzaken, worden darminvaginaties over het algemeen veroorzaakt door poliepen met een diameter van $15 \mathrm{~mm}$ of groter. De huidige richtlijn is dan ook dat tijdens een controle-endoscopie in ieder geval alle poliepen van $15 \mathrm{~mm}$ en groter worden weggehaald om acute invaginaties te voorkomen.

In de loop van de twintigste eeuw werd uit epidemiologisch en later moleculair onderzoek duidelijk dat het syndroom van Peutz-Jeghers tevens is geassocieerd met 


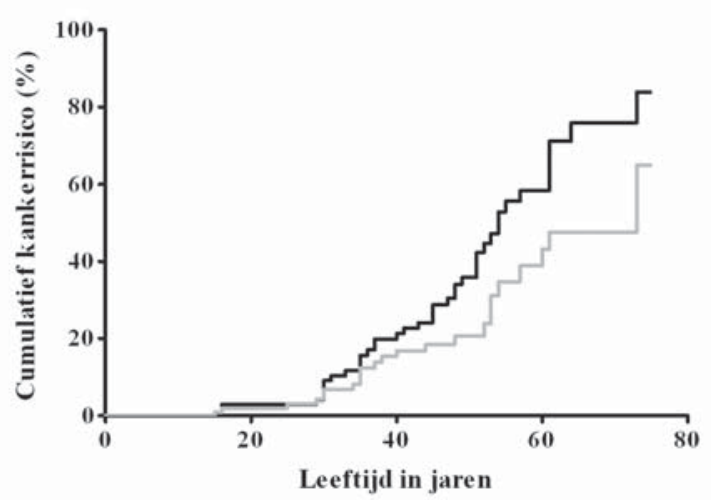

Afb. 3. Cumulatief kankerrisico bij het syndroom van Peutz-Jeghers naar leeftijd. Zwarte lijn: cumulatief kankerrisico ongeacht de locatie. Grijze lijn: cumulatief kankerrisico in het maag-darmkanaal (Bron: Van Lier et al, 2011b).

een sterk verhoogd risico op het krijgen van kanker op jonge leeftijd. Patiënten ontwikkelen niet alleen maligniteiten in het maag-darmkanaal (waaronder maag, dunne darm, dikke darm en pancreas), maar ook in andere organen zoals longen, borsten, ovaria, uterus en cervix uteri (intermezzo 1). Vanwege het zeldzaam voorkomen van het syndroom van Peutz-Jeghers zijn grote onderzoeken voor de nauwkeurige berekening van risico's moeilijk uit te voeren. Een systematisch literatuuronderzoek van 20 cohortonderzoeken met in totaal 1.644 patiënten toonde een cumulatief kankerrisico van $37-93 \%$ op een leeftijd van 70 jaar en een relatief risico van 10 tot 18 in vergelijking met de algemene bevolking (Van Lier et al, 2010a). De gemiddelde leeftijd waarop patiënten kanker kregen was 42 jaar. Het ging vooral om kanker in colorectum, borst, maag, dunne darm en pancreas. Een onderzoek in het Nederlandse patiëntencohort van 133 patiënten liet een cumulatief kankerrisico zien van $20 \%$ op een leeftijd van 40 jaar en van $76 \%$ op een leeftijd van 70 jaar (afb. 3) (Van Lier et al, 2011b). Voor gastro-intestinale kanker was dit risico respectievelijk 12 en 51\% (afb. 3). Mede door dit verhoogde kankerrisico hebben patiënten met het syndroom van Peutz-Jeghers een lagere levensverwachting. Van de 133 patiënten uit de eerder genoemde onderzoeken overleden 42 patiënten op een gemiddelde leeftijd van 45 jaar; in tweederde van de gevallen was kanker de oorzaak van overlijden. Het kankerrisico bleek een factor 4,8 hoger te zijn voor vrouwen dan voor mannen. Dit verschil wordt veroorzaakt doordat vrouwen met het syndroom van Peutz-Jeghers ook een verhoogde kans hebben op borsten gynaecologische kankers.

Naast gynaecologische kankers ontwikkelen vrouwen met het syndroom van Peutz-Jeghers vaker benigne ovariumtumoren, zogenoemde 'sex-cord' stromatumoren. Deze tumoren zijn geassocieerd met hyperoestrogenisme, dat kan leiden tot vroegtijdige puberteit. Mannen lijken vaker testiculaire Sertoli celtumoren te ontwikkelen die ook hormonaal actief zijn en klachten veroorzaken van gynaecomastie, snelle groei, verouderde botleeftijd en verhoogde oestrogeenlevels.
Hoewel het genetisch defect bij het syndroom van Peutz-Jeghers bekend is, is het exacte mechanisme van het ontstaan van kanker in deze patiëntengroep nog niet opgehelderd. Enkele onderzoeken beschrijven een zogeheten hamartoma-adenoma-carcinomasequentie, waarbij de hamartomen in het maag-darmkanaal als premaligne tumoren worden beschouwd. Toch lijkt dit niet waarschijnlijk. Er kunnen adenomateuze of zelfs carcinomateuze veranderingen ontstaan in hamartomen, maar dit is zeldzaam. Daarnaast neemt het aantal poliepen in het maag-darmkanaal af met de leeftijd, terwijl het kankerrisico juist toeneemt. Ook correleert de locatie van de gastro-intestinale kanker niet altijd met de locatie van de hamartomen en bovendien hebben patiënten met het syndroom van PeutzJeghers ook een verhoogd risico op het krijgen van kanker in andere orgaansystemen. Tevens moet er rekening gehouden worden met het fenomeen pseudo-invasie. Hiervan is sprake als het epitheel van een hamartoom pseudo-carcinomateuze invasie vertoont in de spierlaag. Histologisch kan dit worden verward met een invasief carcinoom. Pseudoinvasie is beschreven in ongeveer $10 \%$ van alle poliepen in de dunne darm en kan van een invasief carcinoom worden onderscheiden door het ontbreken van cellulaire atypie (Westerman et al, 1997). Beoordeling door een gespecialiseerd patholoog kan hierbij behulpzaam zijn. Het is dus waarschijnlijker dat hamartomen en carcinomen 2 verschillende entiteiten van het syndroom van Peutz-Jeghers zijn.

\section{Controle}

Vanwege het complicatierisico van de darmpoliepen en het verhoogde risico op kanker, is de zorg voor patiënten met het syndroom van Peutz-Jeghers voornamelijk gericht op controle. Tot op heden zijn er geen gecontroleerde onderzoeken gepubliceerd over de effectiviteit hiervan. De $\mathrm{Ne}^{-}$ derlandse Peutz-Jeghers-syndroom-werkgroep heeft recent een advies opgesteld voor Nederlandse patiënten, gebaseerd op de mening van deskundigen en klinische ervaring (tab. 2). Op jonge leeftijd is de controle gericht op het detecteren en verwijderen van darmpoliepen om complicaties zoals bloedingen en invaginaties te voorkomen. In het algemeen zijn symptomatische poliepen en poliepen van $15 \mathrm{~mm}$ of groter een indicatie voor poliepectomie. Op volwassen leeftijd breidt het controleprogramma zich uit en richt het zich tevens op vroege opsporing van kanker. Voor mannen betreft dit regelmatige controle van het gehele maag-darmkanaal. Vrouwelijke patiënten wordt daarnaast geadviseerd vanaf 25-30 jaar jaarlijks borst- en gynaecologisch onderzoek te ondergaan. Controle van de pancreas met kernspinresonantie (MRI) of endoscopische echomethoden lijkt veelbelovend, maar wordt in Nederland op dit moment alleen in onderzoeksverband verricht.

\section{Medicamenteuze therapie}

Specifieke medicamenten, waaronder het immunosuppressivum everolimus, kunnen mogelijk worden gebruikt als (preventieve) behandeling van hamartomen en carcinomen. In Nederland werd een 46-jarige patiënt met het syndroom 


\begin{tabular}{|lll|}
\hline Onderzoek ${ }^{1}$ & Start leeftijd & Interval \\
\hline Anamnese: lichamelijk onderzoek (incl. palpatietesten) en Hb-controle & 10 jaar & 1 jaar \\
Videocapsuleendoscopie (VCE) en/of MRI-enteroclyse ${ }^{2}$ & 10 jaar & $2-3$ jaar \\
Gastroduodenoscopie & 20 jaar & $2-5$ jaar (afhankelijk van de bevindingen) \\
Colonoscopie & $25-30$ jaar & $2-5$ jaar (afhankelijk van de bevindingen) \\
MRI-onderzoek en endo-echografie van de pancreas & 30 jaar & 1 jaar (alleen in onderzoeksverband) \\
MRI-mammae & 25 jaar & 1 jaar \\
Mammografie en MRI-onderzoek & 30 jaar & 1 jaar ${ }^{3}$ \\
Cervixcytologie, transvaginale echografie, CA-1254 & $25-30$ jaar & 1 jaar \\
& & \\
& & \\
${ }^{1}$ Eerder en/of frequenter onderzoek bij klinische verschijnselen. & \\
${ }^{2}$ Indien het endoscopisch onderzoek poliepen toont is MRI-enteroclyse aan te bevelen om de exacte locatie en grootte van de poliepen \\
te bepalen. Poliepen $>10-15$ mm in diameter zijn een indicatie voor dubbel-ballon enteroscopie (DBE) met poliepectomie. \\
${ }^{3}$ Alternerend mammografie en MRI-onderzoek. \\
${ }^{4}$ Tumormarker voor ovariumcarcinoom.
\end{tabular}

Tabel 2. Controleadvies voor patiënten met het syndroom van Peutz-Jeghers zoals geformuleerd door de Nederlandse Peutz-Jeghers syndroom werkgroep (Van Lier et al, 2010a).

van Peutz-Jeghers met een vergevorderd pancreascarcinoom behandeld met everolimus (Klümpen et al, 2010). De tumor liet partiële respons op de behandeling zien en bovendien verdwenen grote hamartomen in de dikke darm. Verder klinisch onderzoek moet uitwijzen of deze medicamenten inderdaad een effectieve behandeling kunnen zijn voor patiënten met het syndroom van Peutz-Jeghers.

\section{Psychische belasting}

Het syndroom van Peutz-Jeghers gaat gepaard met een aanzienlijke en chronische ziektelast. Bovendien ondergaan patiënten regelmatig invasieve onderzoeken. Dit kan de levenskwaliteit van patiënten beïnvloeden. Daarnaast kunnen bezorgdheid om het invaginatie- en kankerrisico en het overdragen van de ziekte op eventuele kinderen ook stress veroorzaken. De psychische klachten van patiënten met het syndroom van Peutz-Jeghers zijn met behulp van vragenlijsten onderzocht (Woo et al, 2009; Van Lier et al, 2010b). Hieruit bleek dat zij meer emotionele en mentale moeilijkheden ervaren dan fysieke beperkingen. Zij hadden een slechtere algemene gezondheidsperceptie en een slechtere mentale levenskwaliteit in vergelijking met de algemene bevolking. Bovendien voelden patiënten zich beperkt in het dagelijks functioneren vanwege de ervaren emotionele problemen. Hoewel het ene onderzoek concludeerde dat patiënten met het syndroom van Peutz-Jeghers milde depressieve klachten hebben, kon het andere onderzoek deze bevinding niet bevestigen. Toch moet psychosociale zorg worden overwogen door artsen die betrokken zijn bij de zorg voor patiënten met het syndroom van Peutz-Jeghers.

\section{Conclusie}

Aangezien 95\% van de patiënten typische pigmentaties op de lippen heeft, kunnen tandartsen een belangrijke rol spelen bij de detectie van het syndroom van Peutz-Jeghers en bijdragen aan een gerichte verwijzing van patiënten naar een klinisch geneticus en/of een (gespecialiseerde) maagdarm-leverarts.

\section{Literatuur}

* Bosman FT, Carneiro F, Hruban RH, et al. WHO classification of tumours of the digestive system. Geneve: World Health Organization, 2010.

* Hemminki A, Markie D, Tomlinson I, et al. A serine/threonine kinase gene defective in Peutz-Jeghers syndrome. Nature 1998; 391:184-187.

* Klümpen HJ, Queiroz KC, Spek CA, et al. mTOR inhibitor treatment of pancreatic cancer in a patient with Peutz-Jeghers syndrome. J Clin Oncol 2011; 29: e150-153.

* Lier MGF van, Wagner A, Mathus-Vliegen EMH, et al. High cancer risk in Peutz-Jeghers syndrome: a systematic review and surveillance recommendations. Am J Gastroenterol 2010a; 105: 1258-1264.

* Lier MGF van, Mathus-Vliegen EMH, Leerdam ME van, et al. Quality of life and psychological distress in patients with Peutz-Jeghers syndrome. Clin Genet 2010b; 78: 219-226.

* Lier MGF van, Mathus-Vliegen EMH, Wagner A, et al. High cumulative risk of intussusception in patients with Peutz-Jeghers syndrome: time to update surveillance guidelines? Am J Gastroenterol 2011a; 106: 940-945.

* Lier MGF van, Westerman AM, Wagner A, et al. High cancer risk and increased mortality in patients with Peutz-Jeghers syndrome. Gut 2011b; 60: 141-147.

* Lodish MB, Stratakis CA. The differential diagnosis of familial lentiginosis syndromes. Fam Cancer 2011; 10: 481-490.

* Westerman AM, Velthuysen MLF van, Bac DJ, Schouten WR, Wilson $J H$. Malignancy in Peutz-Jeghers syndrome? The pitfall of pseudoinvasion. J Clin Gastroenterol 1997; 25: 387-390.

* Woo A, Sadana A, Mauger DT, Baker MJ, Berk T, McGarrity TJ. Psychosocial impact of Peutz-Jeghers syndrome. Fam Cancer 2009; 8: 59-65.

\section{Summary}

\section{Peutz-Jeghers syndrome}

Peutz-Jeghers syndrome is a rare, autosomal dominant inherited disorder, 
which is characterized by mucocutaneous pigmentations, gastrointestinal polyposis and an increased risk of cancer. It is caused by germline mutations in the LKB1 tumour suppressor gene, as a result of which hamartomatous polyps can develop already at an early age, which may cause various complications, including abdominal pain, anaemia, and acute intestinal obstruction. Patients have an increased risk of developing cancer, in the gastroinstestinal tract and in other organs. As a result of the risk of complications related to the hamartomatous polyps and the increased risk of cancer, the medical management mainly consists of surveillance. Upper and lower endoscopies are recommended for surveillance, the small bowel should be investigated with magnetic resonance imaging and regular inspection of the pancreas with imaging techniques is recommended. Women are advised to seek regular breast- and gynaecological screening from an early age. The pathogenesis of hamartomas and carcinomas is unclear. More insight into the molecular background might lead to targeted medicinal therapies for patients with this syndrome.

\section{Bron}

S.E. Korsse' ${ }^{1}$, M.E. van Leerdam², E. Dekker ${ }^{3}$

Uit ' de afdeling Maag-, Darm- en Leverziekten van het Erasmus Universitair Medisch Centrum te Rotterdam, 2het Nederlands Kanker Instituut/ Antonie van Leeuwenhoek Ziekenhuis te Amsterdam en ${ }^{3}$ het Academisch Medisch Centrum te Amsterdam

Datum van acceptatie: 19 juli 2012

Adres: dr. E. Dekker, AMC Amsterdam, postbus 22660,

1100 DD Amsterdam

e.dekker@amc.uva.n

\section{Verantwoording}

De afbeelding 3 is met toestemming van de BMJ Publishing Group overgenomen uit Van Lier et al, 2011b. 